\title{
Traduzindo no Atlântico Negro: por uma práxis teórico-política de tradução entre literaturas afrodiaspóricas
}

\author{
Denise Carrascosa ${ }^{1}$
}

Resumo: Este artigo-performance foi fruto de comunicação apresentada ao 50. LATIS, em setembro de 2015, tendo funcionado como uma reflexão ainda muito parcial sobre a minha trajetória de pesquisa sobre tradução entre as literaturas afrodiaspóricas. Como exercício teórico-crítico, ele propõe um conjunto de parâmetros e diretrizes de trabalho para o enorme acervo de textos literários produzidos a partir da experiência transatlântica pós-escravista nas Américas, entendendo a tradução como ferramenta poderosa de produção estético-ética de um vigoroso diálogo intercultural que ainda está por vir.

See what I mean? Look to yourself. You free. Nothing and nobody is obliged to save you but you.

Seed your own land ${ }^{2}$.

(Toni Morrison, Home)

Começando pelo fim, gostaria de iniciar provocando um pouco o tema da "afrodiasporicidade", que servirá de motor para toda a discussão que me interessa, como intelectual negra e afro-baiana, sobre a práxis contemporânea da tradução. Nesse sentido e sem muitos atalhos, o conceito de diáspora, em sua

1 Professora Adjunta de Literaturas Anglófonas da Universidade Federal da Bahia (denise.carrascosa@ ufba.br)

2 Entende o que eu digo? Olhe pra si mesma. Você é livre. Nada nem ninguém é obrigado a te salvar, a não ser você mesma. Semeie sua própria terra. (tradução minha) 
dimensão mítica, está intimamente trançado com a narrativa bíblica do Exxodo do povo hebreu, escravizado pelo faraó do Egito e sua libertação do cativeiro sob a liderança de um grande líder, Moisés, que os guia em um tortuoso retorno à Terra Prometida. Segundo Stuart Hall,

esta é a ur-origem daquela grande narrativa de libertação, esperança e redenção do Novo Mundo, repetida continuamente ao longo da escravidão (...) ela tem oferecido sua metáfora dominante a todos os discursos libertadores negros do Novo Mundo (HALL, 2003, p. 29).

Conectada ao conceito "afro", o mito da diáspora ganha os contornos e a força da história de genocídio e migração forçada dos povos africanos que, antes de serem trazidos às Américas, por força do projeto colonial escravocrata europeu, foram invadidos no curso de seu próprio tempo-espaço e tiveram violentada a sua própria história.

A noção de "afrodiáspora", portanto, na medida de seus deslocamentos e ressignificações politicamente estratégicas, carrega consigo a força, não apenas espacial do deslocamento territorial em forma de iter narrativo (no contraditório entre escravidão-liberdade); mas também movimenta o eixo do tempo em chave mítico-cíclica, que faz girar as noções lineares e causalistas eurocêntricas de passado e presente que construíram "a" história oficial e legível, articulando paradigmas importantes das contraculturas negras da modernidade. Para Paul Gilroy:

The idea of diaspora might itself be understood as a response to these promptings - a utopian eruption of space into the linear temporal order of modern black politics which enforces the obligation that space and time must be considered relationally in their interarticulation with racialised being (GILROY, 1993, p. 1998)

Essa demanda por uma articulação necessária entre tempo e espaço nas práticas contraculturais negras modernas e seus processos de subjetivação traduz o modo de funcionamento de um dispositivo político fundamental de reversão de imaginários embranquecidos: o agenciamento de nossas formas de produzir narrativas, valores e sujeitos e, obviamente, as relações de poder que daí decorrem e que estruturam o funcionamento das sociedades contemporâneas, a partir do coração daquilo que as torna possíveis - a linguagem.

Em uma palavra ou toque de tambor: o tempo-espaço da linguagem é a arena de luta. E a "afrodiasporicidade", mais que um conceito, pode ser usado como sua força agonística que destitui e reconstitui territórios. Seus deslocamen- 
tos, movimentações e reversões contraculturais negras se disseminam em vários espaços e tempos, desfazendo a unidade centrípeta da nação e suas ilusões narrativas subalternizantes; gerando uma teia de performances que não se reunificam ou retornam para serem aprisionadas em um lugar do passado mítico africano, ao contrário, a partir de sua pujança, projetam-se como potência contemporânea, portanto ressonante e intempestiva.

Assim como a música, o teatro e o cinema negros e suas demais práticas performáticas e interartísticas, os textos literários afrodiaspóricos têm formulado narrativas, sons e imagens que gestam e reoperacionalizam os sentidos de viagem, perda e exílio, com função menemônica de produzir memória social e consciência de grupo nos processos de invenção e reinvenção da identidade e constituição do espaço nomeado pela metáfora cartográfica de Paul Gilroy:

(...) a non-traditional tradition, an irreducibly modern, ex-centric, unstable and asymmetrical cultural ensemble that cannot be apprehended through the manichean logic of binary coding (GILROY, 2003, 1998).

(...) uma tradição não-tradicional, um conjunto irredutivelmente modern, ex-cêntrico, instável e assimétrico, que não pode ser apreendido através da lógica de código binário" (tradução minha).

Nessa direção rizomática que constitui menos um novo território e mais uma zona de forças, como consigo imaginar O Atlântico Negro pensado por Gilroy, xs escritorxs negrxs e suas produções literárias têm enfrentado problemáticas e performatizado suas subjetividades a partir de uma série de questões e modos de ação, tais como: materialização de uma densidade subjetiva negro-feminina na construção de personagens (Conceição Evaristo e Toni Morrison); investimento em uma multiplicação de papéis intelectuais (Luiz Gama e Langston Hughes); atualização da ancestralidade africana através do imaginário do candomblé (José Carlos Limeira); conexões entre o público e o privado através de memorialismo e autoficção (Oswaldo de Camargo, Alice Walker, Ana Maria Gonçalves); força micropolítica de uma poesia do cotidiano (Maya Angelou, Sérgio Vaz e Gwendolyn Brooks); força poética para sobrevivência urbana pelo panafricanismo (Nelson Maca); rap-filosofia do Public Enemy e dos Racionais MC's; poesia dub como renarrativização da história (Afua Cooper); dor da vida urbana na favela e no asfalto (Paulo Lins e Chester Himes); erotismo e direito ao próprio corpo (Mel Adún e Guellwaar Adún do coletivo soteropolitano Ogum's Toques Negros); homoafetividades negras (Alex Simões e Ari Sacramento, do coletivo soteropolitano Ogum's Toques Negros); reversão do imaginário colonizado e apaziguador do carnaval 
baiano (Fábio Mandingo); uso da potência de uma literatura expandida e derramada em outras artes (Ricardo Aleixo); ironia pós-moderna reversora do imaginário colonial-racista (Cidinha da Silva e Jamaica Kincaid); dramatização de um protagonismo negro entre a individuação e a comunidade (Abdias Nascimento, Wole Soynka, Susan Lori Parks, Janus Adams, Coletivo Bando de Teatro Olodum em Salvador, Coletivo Sistren em Kingston); dramatização da condição do imigrante e do sujeito pós-colonial desterritorializado (Chimamanda Adichie e Teju Cole).

Muito longe de ser exaustivo, este elenco comparece nesta comunicação como forma ainda indicial de ligar os pontos de uma constelação de assinaturas negras fortes que produzem luminescência visibilizadora do Atlântico Negro e que demandam o desenvolvimento de uma escuta atenta para suas produções, que nos soam cada vez mais como uivos noturnos de uma matilha dispersa de corpos tenazes que se reclamam e, cada vez mais, desejam encontros que ampliem a sua potência de (re)agir.

Esses encontros, porém, solicitam-se pela linguagem e na linguagem e, como estamos falando de poéticas que se fazem em língua diferentes, a demanda da tradução interlinguística é cada vez mais intensa e se deixa expressar em pontos diversos do Atlântico Negro. No Brasil, o importante trabalho de Maria Aparecida Andrade Salgueiro já vem criando essa interface entre as literaturas afro-brasileira e afro-americana de modo mais longevo e persistente, nos campos interconectados da tradução e da literatura comparada. Do lado norte da América Negra, Geri Augusto, professora do Departamento de Estudos da África e da Diáspora da Brown University, já busca refletir sobre "uma práxis negra transnacional de tradução", intitulando artigo seu ainda não publicado sobre o tema: "A língua não deve nos separar!"

A tradução, portanto, desponta no Atlântico Negro como tarefa política no sentido spivakiano de trabalho forte com a linguagem como agente produtor de identidade, subalternidade e, ao mesmo tempo, em sua dimensão retórica, como potencial fator gerador de disseminação subversiva. Para Gayatri Spivak, no artigo "The Politics of Translation":

(...) the translator must surrender to the text. She must solicit the text to show the limits of the language that the text wards off, in its special manner (...) translation is the most intimate act of reading. Unless the translator has earned the right to become the intimate reader, she cannot surrender to the text, cannot respond to the special call of the text. (SPIVAK, 2004, p. 372) (...) a tradutora deve render-se ao texto. Ela deve solicitar o texto para revelar os limites linguísticos que ele tensiona de forma especial (...) a tradução 
é o ato de leitura mais íntimo. A menos que a tradutora tenha adquirido o direito de tornar-se uma leitora íntima, ela não pode render-se ao texto, não pode responder ao chamado especial do texto (tradução minha).

A tarefa tradutória, nesse sentido ético-político, processa-se em um double bind que agencia, ao mesmo tempo, a) o sujeito da tradução em sua relação erótica com o texto a traduzir, relação de amor em que o texto literário constitui dimensão de sua própria intimidade e b) a abertura do eu para o outro da cultura, através da linguagem, dimensão coletiva com a qual o tradutor produzirá uma comunidade por vir. Essas duas instâncias fazem acoplar-se o privado e o público de forma a fazer funcionar o dentro e o fora do sujeito tradutor a partir de uma dobradiça que me interessa pensar como "função-tradutor".

Para definir a "função-tradutor", é preciso, em primeira instância, operar por exclusão (duas negações): 1) não representa univocamente uma atividade criativa e/ou profissional; b) não encontra correspondente em um sujeito que realiza esta atividade. Por outro lado, será ferramenta de trabalho, conceito operatório no sentido deleuziano, para crítica e produção do trabalho tradutório. Derivando do mecanismo teórico "função-autor" (FOUCAULT, 2001) servirá para pensar o funcionamento da produtividade deste trabalho na ordem do discurso em sua dimensão estético-ética.

Pensar, assim, o papel do tradutor do ponto de vista de um funcionamento descentrado de discursividade em que o sujeito é pensado não apenas como indivíduo - efeito do discurso, mas também como função do discurso, em regime rizomático, pode trançar-se de modo suave ao exercício de um pensamento pós-estrutural efetivamente mais radicalizante que pense a linguagem, não como compartimento de sentidos traduzíveis por equivalência, mas como zona significante de deslizamento de significados que não pré-existem ao discurso, mas que são produzidos na cena mesma dos atos de fala a depender de suas contingências.

No caso da tradução dos textos literários negros, se pensada contra o fundo de toda problemática da Afrodiáspora e do Atlântico Negro, como definidos anteriormente, a dobradiça política entre a) o sujeito da tradução e b) o outro da cultura a ser traduzida via linguagem ganha uma intensidade ainda mais forte. Desdobro, então, a seguir, esses dois encaminhamentos, iniciando-me pelo segundo: a questão de maior densidade coletiva - a linguagem.

Nas contraculturas afrodiaspóricas, em suas produções artístico-culturais, encontramos uma presença forte de rastros que nos endereçam genealogicamente aos processos mais delicados e invisíveis da escravidão e colonização, que deixaram marcas no corpo e imaginário das sociedades estruturadas por tais regimes, na 
medida em que nenhum gesto genocida elimina por completo a força da cultura que decide violentar, mormente se falamos de milhões e milhões de sujeitos traficados para territórios estrangeiros. Eles foram destituídos de quase tudo. Mas aqueles que suportaram a violência, que não adoeceram ou morreram, ficaram apenas com o que tinham de mais potente - os seus próprios corpos.

Desses corpos de sobreviventes, produziram-se e disseminaram-se formas, ritmos, ritos, gestos, imagens, sabores e línguas, enfim todos os fatores necessários à produção de uma economia simbólica potente para inseminar de modo constante, longevo e, adiantaria até performativo, a chamada "cultura ocidental". A cultura afrodiaspórica operou nas Américas coloniais e escravocratas uma espécie de tradução intercultural intensiva dos modos de fazer cultura, funcionando como o que penso poder chamar de phármakon - indecidível de potência paradoxal - conceito filosófico de J. Derrida "exumado" do texto platônico - Fedro).

O phámakon é esse suplemento perigoso que entra por arrombamento exatamente naquilo que gostaria de não precisar dele e que, ao mesmo tempo, se deixa romper, violentar, preencher e substituir, completar pelo próprio rastro que no presente aumenta a si próprio e nisso desaparece (DERRIDA, 1997, p. 46).

Este veneno/remédio pensado como mecanismo instilado pelo "trabalho da tradução", como simulacro deleuziano cujo perigo apresenta-se na sedução fatal de uma reduplicação infinita - proliferação descontrolada (DELEUZE, 2007), pode nos oferecer um ponto de vista crítico surpreendente para as potencialidades de um trabalho de produção de sentidos que pode entrar por arrombamento exatamente naquilo que gostaria de não precisar dele.

O phármakon afrodiaspórico, que permanece ativo nos textos culturais negros da diáspora, produzindo sua força nos limites do que se pensa como "cultura ocidental", está materializado e se faz visível em uma série diversa de traços intensivos, tais como: a) a síncopa musical - que aparece no blues, samba, jazz, reggae, dub, rap - um tempo intervalar que solicita o corpo para o movimento e a ação, liberando-o da repressão moral e subjugação laborativa (SODRÉ, 1998); b) o jogo de corpo - que encontra o melhor abrigo na técnica da capoeiragem - que produz o deslocamento constante de posições e o desvio estrategicamente produtivo do limite da violência da lei (SODRÉ, 2005); c) o feitiço e o mistério - que promove a flutuação dos sentidos, a polissemia de uma suposta origem, minando a invenção unilateral de "uma" verdade fundadora, seduzindo-a (SODRÉ, 2005); d) opulência e explosão de formas - nos corpos, na comida, nos 
sabores e cores - espécie de estética barroca que cria dobras de dobras de dobras ad infinitum e gesta uma infinidade de encontros imprevistos em encruzilhadas e tranças; e) economia linguística - que reutiliza as línguas coloniais europeias, fazendo das língua crioulizadas em menor ou maior medida (respectivamente o Afro-Português ${ }^{3}$ e do Black English, por exemplo) menos um arquivo morto de palavras e regras morfo-sintáticas e mais um dispositivo performático acionado contingencialmente, pelo corpo, nas diversas cenas discursivas do cotidiano.

Esse conjunto de traços, que derivaram, dentre tantos outros, da força cultural afrodiaspórica são fundamentais ao exercício político de tradução de seus textos literários, mesmo porque eles estão aí intimamente imbricados, fazendo parte dessa matriz de produção. Portanto, na instância da linguagem, como uma das faces da dobradiça da tarefa política da tradução, é preciso acioná-los. Preciso porque necessário e preciso porque deve haver uma precisão estético-ética nessa empreitada, coerente com a função-tradutor do Atlântico Negro, qual seja: intensificação dos rastros da cultura afrodiaspórica no sentido de que sua força conecte os pontos ainda dispersos desse mapa imaginário e geste novas geografias menos geopolíticas e mais "geo-éticas".

Para que alguém se possa investir nessa tarefa intensamente mobilizadora, não é difícil entender que precise estar fortemente afetado pelo vetor de força da afrodiasporicidade em sua experiência subjetiva; seja em seu próprio corpo, que carrega nas cores e nos traços a forma e a força da negritude; seja em seu desejo de uma experiência ética do social, que passe necessariamente pelo diálogo amoroso com um "eu" da cultura que se apresenta como força constitutiva de seu próprio outro. Então, aqui, a primeira questão-dobradiça: o sujeito da tradução - uma das chaves de funcionamento da função-tradutor, pós-estruturalmente descentrada, mas peça intensamente potente para a tarefa da promoção de um Atlântico Negro.

Se pensarmos o papel do tradutor como aquele do pharmakéus - aquele que administra o phámakon, um mágico, um feiticeiro e até mesmo um envenenador (DERRIDA, 1997) - o sujeito tradutor ganha outra dimensionalidade política que apenas as discussões contemporâneas no campo da Ética nos fazem divisar. A função-tradutor - o mecanismo de funcionamento de produção de discursos em desvio e diferença - pensada como força capaz de curar/envenenar as relações de força agenciadas pelos regimes de signos violentamente subalternizantes (nesta discus

3 Nomenclatura produzida a partir de pesquisa coletiva conduzida por grupo da UFBA, coordenada pelos professores Dante Luchesi, Ilza Ribeiro e Alan Baxter, que resultou no livro O português afro-brasileiro. 
são, o racismo etnocida) - pode ser compreendida como agência de sujeitos que, por força de sua intimidade com a dor e a potência subversiva que tais regimes engendram, movimentam um repertório de traços afrodiaspóricos e se deixam afetar amorosamente pelas vozes e textualidades de escritoras e escritores do Atlântico Negro.

Seu exercício tradutório não configura apenas um trabalho instrumental comunicativo de ampliar a acessibilidade e o diálogo entre escrita e leitura nesse outro espaço-tempo imaginado; mas, suplementarmente, produz uma performatividade na linguagem capaz de deslocar, descentrar e rearticular possibilidades de sentidos reversores das forças etnogenocidas. Seu trabalho tradutório configura-se como exercício de uma performance de si, a partir da qual emergem subjetividades transformadas e transformadoras, ciosas de uma construção identitária ética em sua relação a si e sua abertura amorosa para a alteridade, reconheçam-se esses sujeitos como negrxs e/ou brancxs.

"Quando a matilha se põe em círculo ao redor de seu fogo, cada um poderá ter vizinhos à direita e à esquerda, mas as costas estão livres, as costas estão expostas à natureza selvagem". (DELEUZE, GUATARRI, 2006, p. 47).

Que as vozes dispersas afrodiaspóricas (seus artistas como tradutores e seus tradutores como artistas) se ponham em volta do fogo e que suas chispas e uivos se acendam como vaga-lumes e crepitem em direção ao céu noturno da contemporaneidade para fazer acender, fulgurante, um Atlântico Negro.

Então, sim, depois de termos semeado a nossa própria terra, estaremos em casa.

\section{Referências bibliográficas}

AUGUSTO, Geri. A língua não deve nos separar: reflexões para uma práxis negra transnacional de tradução (no prelo).

DELEUZE, Gilles. Lógica do sentido. Trad. Luiz Roberto Salinas Fortes. São Paulo: Perspectiva, 2007.

DELEUZE, Gilles, GUATARRI, Félix. Mil Platôs: capitalismo e esquizofrenia. Vol. 1. Trad. Aurélio Guerra Neto, Celia Pinto Costa. Rio de Janeiro: Ed. 34, 1995.

DERRIDA, Jacques. A farmácia de Platão. Trad. Rogério da Costa. São Paulo: Iluminuras, 1997. 
FOUCAULT, Michel. Estética: literatura e pintura, música e cinema. Trad. Inês Autran Dourado Barbosa. Rio de Janeiro: Forense Universitária, 2001.

GILROY, Paul. The Black Atlantic: modernity and double consciousness. Cambridge, Massachussets: Harvard Univ. Press, 1993.

HALL, Stuart. Da Diáspora: identidades e mediações culturais. Trad. Adelaine La Guardia Resende et al. Belo Horizonte: Ed. UFMG, 2003.

SODRÉ, Muniz. A verdade seduzida: por um conceito de cultura no Brasil. Rio de Janeiro: DP\&A Editora, 2005.

. Samba: o dono do corpo. Rio de Janeiro: Mauad, 1998.

SPIVAK, Gayatri. The politics of translation. In: VENUTTI, Lawrence (Ed.). The Translation Studies Reader. New York, London: Routledge, 2000. 
